\title{
Adherence Assessment of Medication Errors Reporting System at the Public Hospital in Riyadh, Saudi Arabia
}

\author{
Yousef Ahmed Alomi ${ }^{1}, *$ (D), Nisreen Al-Shubaar ${ }^{2}$, Nadia Lubad ${ }^{2}$, Fatimah Ali Albusalih ${ }^{3}$ \\ ${ }^{\prime}$ The Former General Manager of General Administration of Pharmaceutical Care, Former Head, National Clinical \\ Pharmacy and Pharmacy Practice, Former Head, Pharmacy R and D Administration, Ministry of Health, Riyadh, \\ SAUDI ARABIA. \\ ${ }^{2}$ King Salman Hospital, Ministry of Health, Riyadh, SAUDI ARABIA. \\ ${ }^{3}$ College of Clinical Pharmacy, Imam Abdulrahman Bin Faisal University (University of Dammam) Dammam, \\ SAUDI ARABIA.
}

\begin{abstract}
Objective: Medication errors have noteworthy implications in the field of patient safety. Error detection through a dynamic supervision and an efficient error reporting system unveils medication errors and boosts safe practices. The overall goal of this study is to explore the pharmacist's adherence to medication errors reporting system in adults and pediatrics at the public hospital in Riyadh, Saudi Arabia. Methods: This article describes 9 months retrospective cohort study in year of 2015. A retrospective study was conducted on all inpatients at a 300-bed hospital where all medication procedures in each ward were monitored by a clinical pharmacist. The study was conducted at the Public Hospital in Riyadh, Saudi Arabia. The hospital had medication safety officer with medication safety committee. The program led by trained pharmacist and delivered basic medication safety education programs to all health professional. The medication error report consisted of patient demographic information, qualification of committing mistakes, time of errors occurs, type of medication errors, reasons for medication errors, medications stages involved and errors outcome. Results: The total number of reports were 805. The most common adherence documentation of error involving medications were cost related information (100\%), error related information with an average (90.59\%), patient related information $(50.37 \%)$ and drug related information (49.39\%). While the action related information (0.57\%) was harmless. The most common completed of error related information were causes of medication errors 775 (96.3\%) and type of medication errors 770 (95.6\%) followed by outcome of medication errors 764 (94.9\%) and medication process stages involved 711 (88.3\%). While the patient's demographic information completed only (50\%) in reports. Conclusion: Despite the medication error reporting is consider new at the public hospital, the number of reporting was high. The system needs more determination to follow completeness medication errors reporting system and that by development of an electronic reporting system, program awareness and positive documentation system feedback changes in pharmacy practice.
\end{abstract}

Key words: Adherence, Medication errors, Ministry of Health, Public, Riyadh, Saudi Arabia.

Copyright: @ the author(s),publisher and licensee International Journal of Pharmacology and Clinical Sciences. This is an open-access article distributed under the terms of the Creative Commons Attribution Non-Commercial License, which permits unrestricted non-commercial use, distribution, and reproduction in any medium, provided the original work is properly cited.

This is an open access article distributed under the terms of the Creative Commons Attribution-NonCommercial-ShareAlike 4.0 License
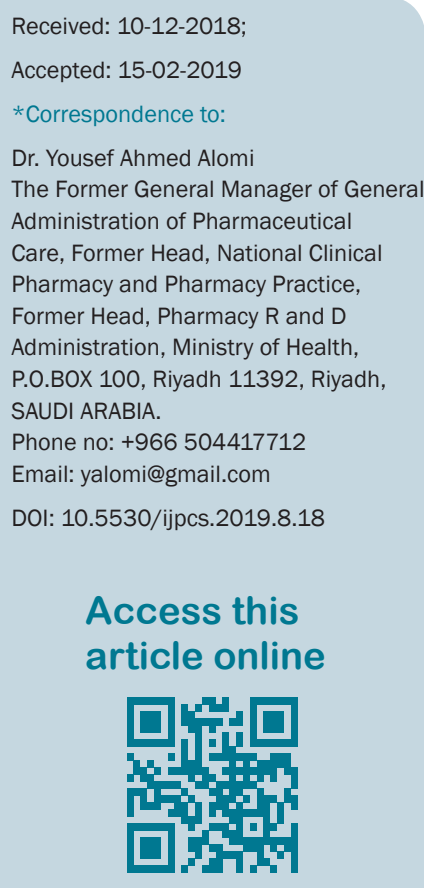

www.ijpcs.net

\section{INTRODUCTION}

Advance of quality of life and good clinical consequences regarding health are the main aims of prescribing medication and administration. These times, human services suppliers and patients themselves had seen that these recognized medicines were similarly connected with deplorable rates of adversities and errors. ${ }^{[1]}$ Past 
examinations focused on the issue and distinguished the causes, for example, inadequately organized prescription or applying transcribed method. ${ }^{[2-4]}$ Nature, incidence and prevalence of prescribing errors for conceded patients were explored. ${ }^{[5]}$ The causes and factors related to these errors were described. ${ }^{[6]}$ Medicine Errors (MEs) are under-detailed in all nations, ${ }^{[7]}$ especially in emerging nations. MEs show a general issue and can cause genuine results for patients, mainly those with intense complex medical conditions. ${ }^{[8]}$ The National Patient Safety Agency revealed that MEs in all care settings in the United Kingdom (UK) occurred in each phase of the prescription treatment process, with $16 \%$ prescribing errors, $18 \%$ dispensing errors and $50 \%$ errors in the administration process. ${ }^{[9]}$

In a study conducted by Samsiah A et al. ${ }^{[10]}$ it was clear that the most common cause of medication errors are due to patients or physicians' failure to follow to the medical reporting systems in the hospitals they work in. The study was applied in Malaysia and it was a nationwide one. Dibbi HM et al. ${ }^{[11]}$ conducted a study to explore the causes and outcomes of medication errors in hospitalized patients were they explored the extent to which medical services providers and patients follow to the medication errors system. Since 1992, FDA has received more than 20,000 medication error reports. The researchers analyzed 2,627 files of patients where they detected 3,963 errors. A number of 1,559 files included one error and 800 files included 2 errors, while 268 included more than 3 errors. The most common cause of errors are due to concentration as 914 patients were not focused $(34.79 \%)$ and 807 errors were due the administration failed to follow to the system. In addition, the study showed that 788 (30\%) of the errors were related to the wrong dosage administration. The results of Dibbi HM et al. ${ }^{[1]}$ confirmed that most of the errors are caused by human factors, which led to 1,223 errors (46.49\%). Besides, the miscommunication led to 920 errors (35.02\%) and failure to read the prescription caused 484 errors (18.43\%). Such medication errors harmed 26 serious cases. Al-Dhawailie $\mathrm{AA}^{[12]}$ provided another proof that following to medical errors reporting system is important to avoid medication errors. Errors should be identified through an active management and effective reporting system, so they could be removed before they can reach or cause harm to patients. The study listed some examples of how misinterpretation the prescription might harm the patients. Higuchi A et al. ${ }^{[13]}$ hassled the importance of computerized medication errors system as it facilitates the process and helps in disabling most of the errors made during the medical service delivery. The goal of this study is to explore the pharmacist's adherence to medication error documentation system at the public hospital in Riyadh, Saudi Arabia.

\section{METHODS}

A cross-sectional study was carried out for a period of 9 months in year of 2015 in inpatient department at the Public Hospital in Riyadh, Saudi Arabia. The study was conducted according to the ethics guidelines set out in the Declaration of Helsinki and written consent from was obtained from the institution. The hospital is formed of 5 floors and with 300 beds. The study included inpatient sections of the hospital.

The hospital provides clinical services in different specialties such as Endocrinology, Nephrology Pediatrics, Cardiology, Internal medicine, Surgery, critical care, The Neonatal Intensive Care Unit (NICU), The Pediatric Intensive Care Unit, Obstetrics and Gynecology in addition to ambulatory care services and emergency services. Also, the hospital pharmacy offers very comprehensive pharmaceutical services including inpatient pharmacy, ambulatory care pharmacy, Total Parenteral Nutrition (TPN) services, drug information services and computerized physician order entry system inpatient and outpatient units. Before three years in 2014, the pharmacy department established medication safety program. Medication safety program initiated at Riyadh Region in 2013. National medication safety program of Ministry of Health and Central committee of medication committee it headed by first author and Riyadh Regional Medication safety committee headed by second author. In particular, a hospital medication safety program managed by part-time pharmacist and the program consisted of medication officer and local committee of medication safety.

The officer monitors all medication errors, adverse drug reaction, drug quality system inside the hospital, Institute Safety Medication Practice (ISMP) guidelines, ${ }^{[14]}$ local standard of accreditation body (Saudi Central Board of Health Care Accreditation) standards and medication safety of Joint commission of Hospital accreditation from United States of America. ${ }^{[15,16]}$ They also felt accountable for medication safety course to all health care professional, physician, pharmacist, nurses etc. and report all medication safety related issues to higher administration and $\mathrm{MOH}$.

Medication officers are responsible for documenting 
Adverse Drug Events (ADEs) using the medication error form. All errors or unforeseen events related with the medication system or a step in the medication process shall be reported using the medication error notification form/medication error sheet whether or not the error reached the patient. The medication error form consists of 2 parts and 40 items including types and causes of medical errors. The form mainly consisted of patient information, description of errors - date and time, medical product involved in the event, impact of the error, consequences, intervention, the sources of medication errors and qualification of committing errors. Suspected medications, drug classification, stage of medication orders, details of reporter, route of administration for medication, the type of medication errors, description and causes of errors, agreement to prevent the errors and the significance of medication errors by using National Coordinating Council for Medication Error Reporting and Prevention (NCCMERP) system. ${ }^{[17]}$ The Microsoft Excel sheet version 10.0 was used for data entry and analysis.

\section{RESULTS}

The total number of reports were 805 . The most common written of error involving medications were cost related information (100\%), error related information with an average (90.59\%),patient related information (50.37\%) and drug related information $(49.39 \%)$. While the action related information $(0.57 \%)$ was harmless. The pharmacist reported all reports (100\%). The most common documentation of error related information were causes of medication errors 775 (96.3\%) and type of medication errors 770 (95.6\%) followed by outcome of medication errors 764 (94.9\%) and medication process stages involved 711 (88.3\%). While the patient's demographic information completed only (50\%) in reports.

The qualification of committing errors $3(0.4 \%)$ and suggestion to prevent errors $2(0.25 \%)$ followed by the time of mistakes and reporter information $0(0 \%)$ were balanced prescribing related information. The most common documenations of error related information was cause of the errors 775 (96.3\%), while type of errors $613(82.86 \%)$ was harmless. The highest documentation adherence among drug related information was route of administration 694 (86.6\%), while the least one was drug classification 28 (3.5\%). The highest documentation adherence among prescriber related information was sources of medications errors 773 (96\%), while the least one was time of errors $0(0 \%)$ (Table 1$)$.

\section{DISCUSSION}

The goal of the drug therapy is the achievement of the best therapeutic outcomes and the improvement of the patient's quality of life. Medications safety program at the Public Hospital, Riyadh, Saudi Arabia started after one year of established national medication safety program. The program consisted of several elements including the documentation of medication error events. ${ }^{[18]}$ The form of medications errors designed by general administration of pharmaceutical care was used for process of documentation. The form consisted of five parts included patient, error, recommendations to prevent error, drug and cost avoidance of prevention errors related information. All documentation procedure was carried out manually then converted to excel sheet or survey monkey system for analysis. This is study as part of combined medications safety and quality programs performed in the site hospital pharmacy. Cost avoidance and error related information was the highest part of documentation during the study. Both elements were very critical sections to measure the influence of the medication safety performances in the pharmacy and follow up error-related issues. ${ }^{[19-21]}$ The patient and drug related information was half of adherence documentation. Electronic documentation system was not used by pharmacist. The similar study reported with missing drug history of the patients. ${ }^{[22,23]}$ Prevention of medication error was the least one because of busy pharmacy or work overloaded during medication error documentation. The study findings showed causes, type of error, stages of delivering medications and error consequence the highest documentation adherence, because those information required by national and international accreditation agencies. ${ }^{[15,16]}$ The qualification of committing errors, the recommendations of error prevention and time of medication errors incidences had the highest non-adherence of documentation because of pharmacy workload or non-important pharmacist background for these essentials. Hence, corrective actions targeted priority areas and root causes to prevent recurrence. Thus, Several findings could not compare them with previous investigations. It discover the quality performances of medication error documentation system. The documentation system needs to improve though implementation of electronic documentation of medication errors through clinical design support system and using computerized physician order entry at Ministry of Health hospitals. The strategies explored in this study can support any organization in decreasing rates of medication errors 


\begin{tabular}{|c|c|c|c|c|c|}
\hline No & Type of information & $\begin{array}{l}\text { Number of } \\
\text { answered question }\end{array}$ & $\begin{array}{l}\text { Answered } \\
\text { question \% }\end{array}$ & $\begin{array}{l}\text { Number of non- } \\
\text { answered question }\end{array}$ & $\begin{array}{l}\text { non-answered } \\
\text { question } \%\end{array}$ \\
\hline 1 & \multicolumn{5}{|l|}{ Patient-related information } \\
\hline 1.1 & Age of Patient & 442 & 54.9 & 363 & 45.1 \\
\hline \multirow[t]{2}{*}{1.2} & Patients nationality & 369 & 45.84 & 436 & 54.16 \\
\hline & Average & & 50.37 & & \\
\hline 2 & \multicolumn{5}{|l|}{ Prescriber-related information } \\
\hline 2.1 & Source of medication error & 773 & 96 & 32 & 4 \\
\hline 2.2 & Qualification of committing Errors & 3 & 0.4 & 802 & 99.6 \\
\hline 2.3 & Time of Error & 0 & 0 & 805 & 100 \\
\hline \multirow[t]{2}{*}{2.4} & Department source & 17 & 2.9 & 788 & 97.1 \\
\hline & Average & & 24.82 & & \\
\hline 3 & \multicolumn{5}{|l|}{ Drug-related information } \\
\hline 3.1 & Suspected Drug & 279 & 34.66 & 526 & 65.34 \\
\hline 3.2 & Drug Classifications & 28 & 3.5 & 777 & 96.5 \\
\hline 3.3 & Package Container & 586 & 72.8 & 219 & 27.2 \\
\hline \multirow[t]{2}{*}{3.4} & Route of Administration & 694 & 86.6 & 111 & 13.4 \\
\hline & Average & & 49.39 & & \\
\hline 4 & \multicolumn{5}{|l|}{ Error-related information } \\
\hline 4.1 & Stage involved & 711 & 88.3 & 94 & 11.7 \\
\hline 4.2 & Type of Error & 613 & 82.86 & 192 & 13.4 \\
\hline 4.3 & Cause of error & 775 & 96.3 & 30 & 3.7 \\
\hline \multirow[t]{2}{*}{4.4} & Outcome of Error & 764 & 94.9 & 41 & 5.1 \\
\hline & Average & & 90.59 & & \\
\hline 5 & \multicolumn{5}{|l|}{ Action-related information } \\
\hline 5.1 & Intervention to prevent medication errors & 7 & 0.9 & 798 & 99.1 \\
\hline \multirow[t]{2}{*}{5.2} & $\begin{array}{l}\text { Recommendation to prevent recurrence } \\
\text { of error }\end{array}$ & 2 & 0.25 & 803 & 99.75 \\
\hline & Average & & 0.57 & & \\
\hline 6 & \multicolumn{5}{|l|}{ Cost-related information } \\
\hline 6.1 & Cost avoidance & 805 & 100 & 0 & $0 \%$ \\
\hline
\end{tabular}

and patient safety improvement efforts.

\section{CONCLUSION}

Error reporting and cause analysis are important tools to identify the major roots of medication errors. The medication safety program auditing and quality parameter monitoring is very valuable for healthcare institutions. The adherences of medication error reporting systems should be enhanced by removing barriers and by clarifying the importance and the role of health care professionals. Electronic medication errors documentations are highly suggested to meet all requirements of medication error documentation system. Educational and training programs on drug therapy and related error documentations are mandatory for medical/paramedical students, drug prescribers (doctors) and nurses (administrating drugs) to diminish drug errors and to expand patient safety. Regular and expanding quality measures including compliance parameter for healthcare institutions should be a future target cross over regions at Ministry hospitals in Kingdom of Saudi Arabia.

\section{ACKNOWLEDGEMENT}

None.

\section{CONFLICT OF INTEREST}

The authors declare that there are no conflicts of interest.

\section{ABBREVIATIONS}

MEs: Medicine Errors; UK: United Kingdom; MOH: Ministry of Health; ISMP: Institute Safety Medication Practice; NCC: National Coordinating Council; MERP: Medication Error Reporting and Prevention; KSA: Kingdom of Saudi Arabia. 


\section{ORCID ID}

Yousef Ahmed Alomi (D, https://orcid.org/0000-00031381-628X

\section{REFERENCES}

1. Classen DC, Metzger J. Improving medication safety: The measurement conundrum and where to start. Int J Qual Health Care. 2003;15(Suppl 1):i41-7.

2. Bates DW, Cullen DJ, Laird N, Petersen LA, Small SD, Servi D, et al. Incidence of adverse drug events and potential adverse drug events. Implications for prevention. ADE Prevention Study Group. JAMA. 1995;274(1):29-34.

3. Dean B, Schachter M, Vincent NBC. Prescribing errors in hospital inpatients: their incidence and clinical significance. Qual Saf Heal Care. 2002;11(4):340-4.

4. Dean B, Schachter M, Vincent C, Barber N. Causes of prescribing errors in hospital inpatients: a prospective study. Lancet. 2002;359(9315):1373-8.

5. Dean B, Barber N, Schachter M. What is a prescribing error?. Qual Health Care. 2000;9(4):232-7.

6. Lewis PJ, Dornan T, Taylor D, Tully MP, Wass V, Ashcroft DM. Prevalence, incidence and nature of prescribing errors in hospital inpatients. Drug Saf. 2009;32(5):379-8.

7. Osborne J, Blais K, Hayes JS. Nurses' perceptions: when is it a medication error?. J Nurs Adm. 1999;29(4):33-8.

8. Kozer E. Medication errors in children. Pediatr Drugs. 2009;11(1):52-4.

9. Healey F, Scobie S. Slips, trips and falls in hospital: The third report from the Patient Safety Observatory. National Patient Safety Agency. 2007.

10. Samsiah A, Othman N, Jamshed S, Hassali MA, Wan-Mohaina WM. Medication errors reported to the national medication error reporting system in Malaysia: a 4-year retrospective review (2009 to 2012). Eur J Clin Pharmacol. 2016;72(12):1515-24.

11. Dibbi HM, Al-Abrashy HF, Hussain WA, Fatani MI, Karima TM. Causes and outcome of medication errors in hospitalized patients. Saudi Med J. 2006;27(10):1489-92.

12. Al-Dhawailie AA. Inpatient prescribing errors and pharmacist intervention at a teaching hospital in Saudi Arabia. Saudi Pharm J. 2011;19(3):193-6.

13. Higuchi A, Higami Y, Takahama M, Yamakawa M, Makimoto K. Potential underreporting of medication errors in a psychiatric general hospital in Japan. Int J Nurs Pract. 2015;21(Supp 2):2-8.

14. Conners J, Dager W, Evan M, Gulseth M, Jenkins RWM. ISMP Medication Safety Self Assessment ${ }^{\circledR}$ for Antithrombotic Therapy. The Institute for Safe Medication Practices. 2017.

15. Medication Management (MM). In: National Hospital Standards. $2^{\text {nd }}$ Edition. Saudi Central Board for Accreditation of Healthcare Institutions. 2015;194-211.

16. The Joint Commission. 2016 Comprehensive Accreditation Manuals. Joint Commission Resources. 2016.

17. Hartwig SC, Denger SD, Schneider PJ. Severity-indexed, incident report-based medication error-reporting program. Am J Hosp Pharm. 1991;48(12):2611-6.

18. Alomi YA. National Medication Safety Program at Ministry of Health in Saudi Arabia. J Pharmacovigil. 2015;3(5):e145.

19. Alomi YA, Aldosori N, Alhadab M, Alotaibi NR, Al-Shubbar N, Al-Enazi ADM, et al. The Outcomes of clinical pharmacist consultation visits at ministry of health hospitals in Saudi Arabia: Medication safety and pharmacy research. J Pharm Pract Community Med. 2017;3(3):168-75.

20. Alomi YA, Al-Shubbar NA, Lubad NA. Economics outcomes of medication safety program at public hospital in Riyadh, Saudi Arabia. In Value in Health. 2017;20(5):A32.

21. Alomi YA, Alanazi AA, Alsallouk SA, Almaznai MM, Abu-Alnaja NI, Alduhilan $M$, et al. Cost-efficiency of medication safety program at pediatrics, obstetrics and gynecology hospital, East Province, Saudi Arabia. Value Heal. 2016;19(7):A464.

22. Fitzgerald RJ. Medication errors: The importance of an accurate drug history. Br J Clin Pharmacol. 2009;67(6):671-5.

23. Agrawal A, Aronson JK, Britten N, Ferner RE, Smet PAD, Fialová D, et al. Medication errors: Problems and recommendations from a consensus meeting. Br J Clin Pharmacol. 2009;67(6):592-8.

Cite this article as: Alomi YA, Al-Shubaar N, Lubad N, Albusalih FA. Adherence Assessment of Medication Errors Reporting System at the Public Hospital in Riyadh, Saudi Arabia. Int J Pharmacol. Clin. Sci. 2019;8(2):105-9 